ESTUDO DE MECANISMOS ENVOLVIDOS NA INCORPORAÇ̃̃O DE PROTEÍNAS DURANTE A OVOGÊNESE EM AnO pheles. (*)

Beatriz Ronchi-Teles $(* *)$

Wanderli Pedro Tadei (***)

Carminda da Cruz-Jandim $(* * * *)$

José Wilson dos Santos Meirelles (**)

RESUMO

Ovärios de Anopheles triannulatus foram dissecados 24 e 48 horas apôs as fêmeas te rem sido alimentadas com fonte protéica (sangue), afim de se estudar o seu efeito sobre a ovogênese. Foram analisadas secçöes histológicas, ao nivel da ultraestrutura, e observadas as mudanças morfológicas que ocorrem nas interfaces células foliculares-ovōcito e célula folicular-célula. Foram observados aspectos estruturais que corroboram a hipötese da produçäo exögena das proteinas do vitelo. Os grânulos de vitelo orcoinaram-se principalmente por condensação das vesículas pinociticas formadas na superfîcie do ovócito.

\title{
INTRODUÇÃO
}

0 aspecto principal do estudo da ovogênese nos insetos tem sido a origem das proteinas obtidas pelo ovócito durante a vitelogênese. Discute-se se essas proteínas seriam sintetizadas no próprio ovócito ou a ele chegariam a partir de fontes exógenas. A primeira evidéncia de incorporação de proteínas, a partir da hemolinfa, pelo ovócitofoi dada por Wigglesworth (1943) em Rhodnius prolixus e emalguns aracnídeos. Trabalhos mais recentes sobre a formação e a deposição dos grânulos de proteínas no ovócito têm demons trado que eles são sintetizados extra ovário e obtidos pelo ovócito a partir da hemolin fa, por pinocitose (Telfer, 1960, 1965; Telfer et al., 1982; Bitsch, 1980). As vitelogeninas, proteínas da hemolinfa limitadas ao sexo feminino (Telfer, 1954, 1960), que or $\underline{i}$ ginam as vitelinas do vitelo, são produzidas em vários tecidos. Em numerosos insetos di ferentes essas lipoproteínas são sintetizadas nas células do corpo gorduroso (Shigematsu, 1958, 1960; Hagedorn, 1972, 1973; Brooks, 1969, 1976; Engelmann, 1969, 1971; Engels, 1974; Simöes, 1980). Os dados atuais indicam que a maioria dos insetos apresenta um pro cesso predominantemente exögeno de produção de vitelo e como evidenciaramos estudos ao

(*) Trabalho subvencionado pelo POLONOROESTE/CNPq/ELETRONORTE.

(**) Instituto Nacional de Pesquisas da Amazônia-INPA, Manaus - AM.

(***) Instituto Nacional de Pesquisas da Amazônia/UNESP, Campus de São José Rio Preto. (***k) Universidade Estadual Paulista - UNESP, Campus de Rio Claro. 
nivel da ultraestrutura, a condensaça das vesiculas pinocíticas foi observada en Aedes aegypti (Roth a Porter, 1964); Periplaneta americana (Anderson, 1964); Lygeus kaImii (Kes sel \& Beans, 1962); Panorpa (Bier \& Ramanurty, 1964); Hyalophora cecropia (Stay, 1965; Telfer et al, 1982). Mas em alguiras espécies corro Bombyx terrestris (Hopkins \& King, 1966), Hyalophora cecropia (Anderson \& Telfer, 1969) e, parcialmente en Ephestia kuhniclla (Guel in a Durand, 1960), o processo paroce ser incranvatiano, sendo as proteinas sinteLizadas nas cêlulas foliculares.

Cumbings \& King (1970) demonstraram que em Drosophila uma fração da vitelogenina total é sintetizada no citoplasma do ovöcito, num processo ctaramente endögeno, em adif̧ão às fontes exógenas. O mesmo tendo sido verificado por Bitsch (1980) em Thysanura.

No estudo da dinâmica da ovogênese em espécies de Anopheles, um ponto relevante a ser ressaltado é que a transmissäo da maläria é realizada pelas fêmeas, o que decorre da sua al imentação hemátófaga. Por outro lado, uma al imentaçăo sanguínea é necessária para a maturaçāo dos ovócitos. Considerando este aspecto, neste trabatho sào incluídos dados relacionados a uma faceta do processo reprodutivo, analisando-se mecanismos envalvidos na obtençào do vitelo pelo ovócito, acompanhando-se as modiftcaçóes morfológicas, ac nível da ulcraestrutura, durance seu desenvolvimento.

MATERA. E AIITODOS

Para análise da ultraestrutura dos ovarios. Pêmeas de A. triannulatus fora coleta. das na natureza, transportadas para o laboratörio, para obtensăo de desovas $\varepsilon$, eclodidas as larvas, estas foram manzibas atê atimgirem o estänio adulto. En sequida à emergência dos imagos, depois de am periodo de 24 horas de manutengäo, as fêneas foran alimentadas com sangue humano ffonte protéica) e dissecadas depois de 24 e 48 tworas apos o repasto sanguineo, en glutaraldeido 2,5: em tampäo cacodilata 0,1 M pH 7,2. Ds ovários foran fi xados na mesma solucão por 2 horas a $4^{\circ} \mathrm{C}$. Em seguida lavados ent cammäo e pós-fixados nu

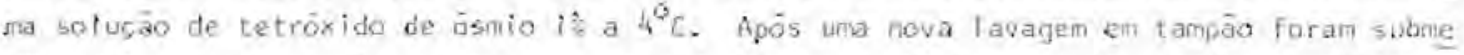
tidos a uma contrastacão, usando-se una solusào aquosa de acetado do uranila a 1 , por uma noire, a $4^{\circ} \mathrm{C}$. Ein seguida foram desidratados por meio de passacens sucessivas enace rona $30 \%, 54 \%, 70 \%, 30 \%$ e $100 \%$, 15 minucos cada banno.

A embebi tóo coi feita de acordo com o seguinte esquema: acetona-araldite $2 ; 1$; ace tona-araldite $3: 1$; acecona-araldite $1: 2$ e resina pura, 1 hora sara.

Finaluente, os ovários forant transferidos para polimerizaçōo durante 72 horas, a $60^{\circ} \mathrm{C}$.

Os blocos foran seccionados num utcramicrözoms - RElCHERT Om $U_{3}$ comi navalfa de vi dro. As seccöes forait contrastadas en acetato de aranila ce citraca do chunto iReynolds, 1963), examinados aum microscopio ZE/SS EM $10 \mathrm{~A}$. 
A estristura dos ovários do gênero Anopheles foi descrita por Christophers (1911) t modificada por Mer (1936). Os ovärios foran separados por fases de desenvolvirento de acordo con as seguintes características:

1 - Folículo com ovö́cito sem grânulos de vitelo;

11 - Folículo ccrn ovócito com grânulos na periferia;

111 - Folículo con ovócito com vitelo ocupando a sua maior parte:

Iv - Folículo con ovócito ocupando a sua maior parte e células nutridoras localizando-se na parte superior;

Y. Ovócito coberto pelo córion, óvulo está pronto pare ser fecundado é posto.

Considerando o estágio de vitelogênesé, os ovários podem ser agrupados de acordo ccri a fase: pré-vitelogènica - I E II; vitelogênica-III e IV; e pós-vitelogénica - V.

Para nue o desenvolvimento se efet ive até a completaraturacāo do ôvula, í necessajrio que a fêrea obtenha um repasto sanguíneo completando assim a vitelogénese. A alimen taça unicamente por carboidratos leva o desenvolvimento do ovócito apenas até o início da fase III. Una fêmea, durante o seu período de vida aduita, passa por värios repastos sanguíneos, produzindo um lote de ovos em cada ciclo gonotrófico que os segue.

A Figura 1 ilustra a estrutura de um folículo completa, fixado após 24 horas de ali nentaçăo (fase vitelogênica), onde aparece uma cēlula nutridora e o ovócito envolto por una camada de celulas folioulares. O ovócito é caracterizado por apresentar grãos de li pídeos, gräos densos de proteínas e um nucleo de forlua irregular. As células nutridoras geralmente apresentam um núcleo volurioso e de contorno irregular, e o nucléolo ben evidente. Observam-se também grãos de lipídeos em seu citoplasma.

Observa-se ainda na Figura 1 que o núcleo das células foliculares tarbém è voluro so, ocupando quase todo o espaço interior da messma; o nuclèola tambēm apresenta esta ca racterística. Este aspecto é rostrado ainda nas Figuras 4 e 6 . Na Figura 5 verifica-se que o citoplasma das células foliculares apresenta um nünera grande de ribossamos, cano tanbèn retículo encoplasmatico e nitocôndrias.

Na Figura 2 fica evidenciado o extenso desenvolvirento dos nücleos das células nu tridoras e foliculares indicando que este fato poderia estar relacionado con urra intensa produção de RNA. Corroborando este aspecto, na Figura 3, cm ampliaçăo maior, observa-se passagem de material do nücleo para o citoplasma da célula nutridora.

o epitélio folicular circunda todo o folículo, estando, na parte superior, en con tato con as cẻlulas nutridoras $e$, na porção inferior, en contato direlanente com o ovócito (Figura 1). Neste ültimo, forañ voservadas diferenclaçöes marcantes relacionadas às mertaranas das células foliculares e do ovócito. Essas madificaçōes poden ser enfoca Jas en dois momentos, em uma primeira etapa, envolvendo a regiäa do epitélio folicular e, em una segunda, envolvendo a ärea de interface epitélio/ovöcito.

Considerando a regía do epitèlio folicular, em contako com o ovócito (Fiqura 4), observam-se espáxos intercelulares restritos àrea do ovocito (Figura 1). Na Figuras 
ė mostrado, de forma ampliada, o material floculento encontrado nesses espaços.

Na regiäo da interface ovöcito/cëlulas foliculares pode-se observar o processo de formaçāo dos gräos de proteínas (Figuras 6 e 7). Nessa regiāo existe una grande diferenciação nas rembranas celulares de arbas as células e, à redidaque a vitelogênese se ini cia, aparecen dobras no membrana plasmática do ovócito, as quais se interdigitam com as das foliculares, aumentando assim a superfície de contato entre elas (Figura7). São fre qüentes as invaginaçōes com conteüdo eletrodenso (Figura 6) e observar-se tambēm microvi losidades formando uma verdadeira nalha ao longo de toda a regiajo de contato. Essas microvilosidades se estendem da superfície do ovärio (Figura 7) e vesículas revestidas (coated vesicles), originadas no fundo dessas microvilosidades, coroam o córtex do ovócito. A fusão dessas vesículas pinocíticas, contendo material eletrodenso, origina os grânulos de proteínas.

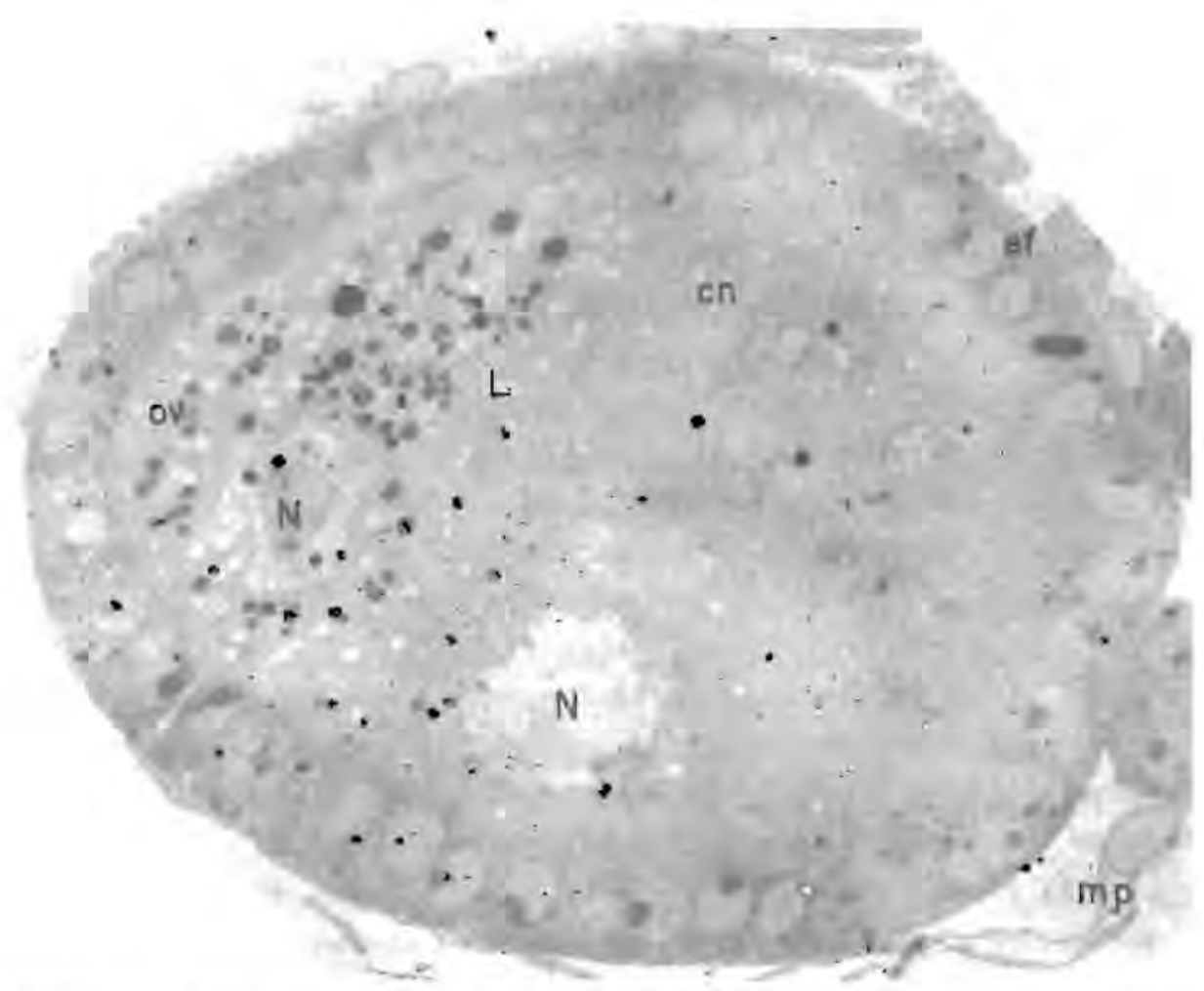

Fig. 1. Fotomicrografia de un folículo fixado 24 horas após alimentaçāo sangüinea, onde aparece uma célula nutridora $(\mathrm{cn})$, o ovócito (ov), envolvidos pelo epítélio fo licular (ef). A célula nutridora é caracterizada pela presenca de um citoplas ma granular e uाa núcleo desenvolvido (N), enquanto que a presença de grảos de lipídeos (L), grãos densos (P), nücleo irreguiar (N) sạo típicos de ovócito em estagio de maturaçăo. Ao redor do folículo aparece a membrana peritoneal (np). $2.450 \mathrm{x}$. 
Esses grânulos apresentam conteúdo muito eletrodenso com um halo claro ao redor, pois a membrana que os envolve se acha afastada (Figura 7).

0 conteŭdo do grânulo assume uma configuração cristalina, quando maduro, (maturação com 48 horas) e apresenta diferentes orientações, provavelmente devida â união de pe quenos grânulos que se cristalizam após a fusão, conforme evidências verificadas na Figura 8. O grânulo protéico totalmente maduro resulta dessas fusões, o que fica evidenciado pelas diferentes orientações encontradas no grânulo em uma única secção que toma o aspecto de uma bola de futebol (Figura 9).

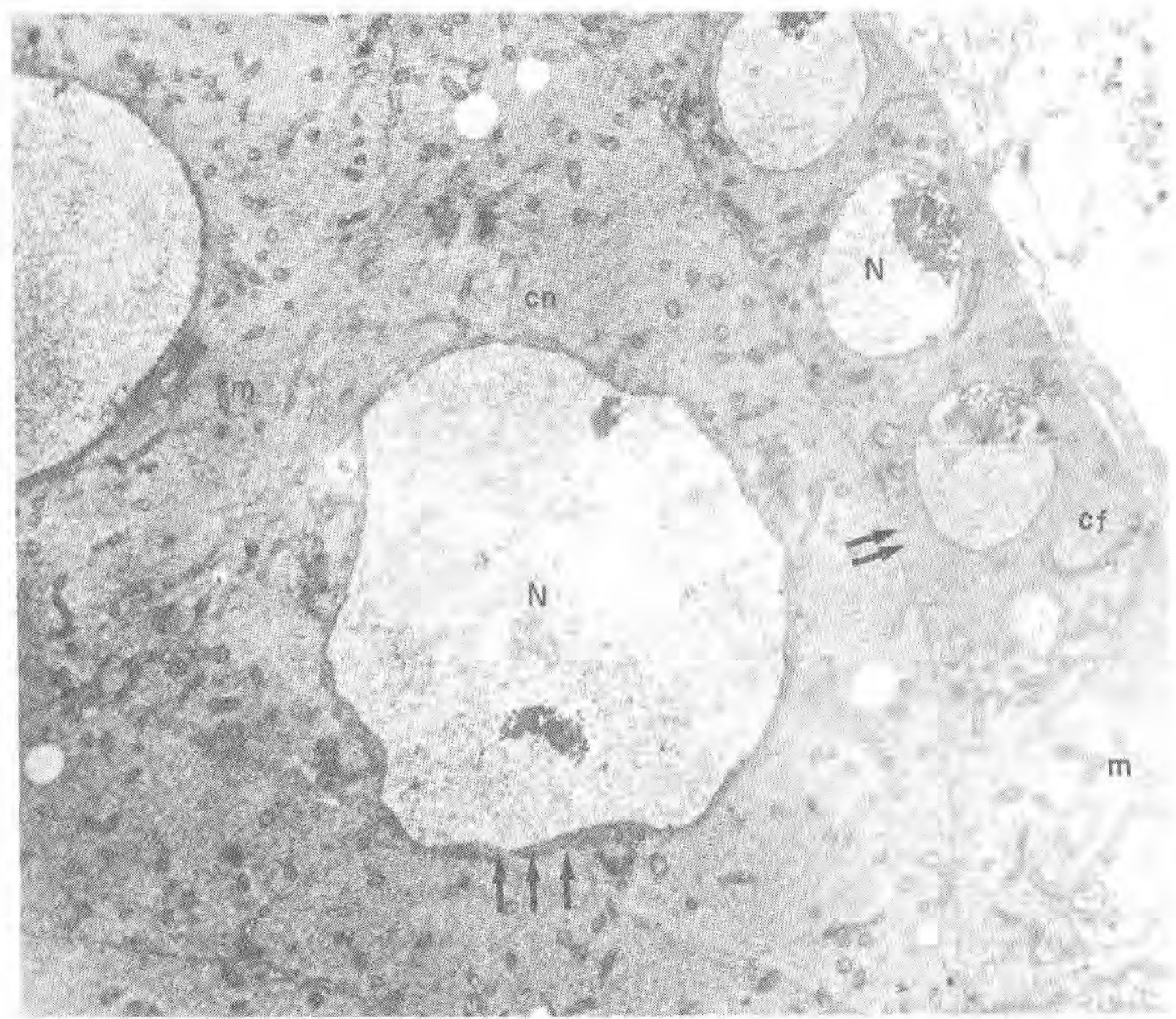

Fig. 2. Fotomicrografia de célula nutridora ( $\mathrm{cn}$ ) em contato (setas duplas) com células foliculares (cf) mostrando seus nücleos (N) desenvolvidos, indicando produçäc de RNA. Nas células nutridoras o material é eliminado para o citoplasma(setas triplas). Mitocōndrias (m). 8.100 X. 


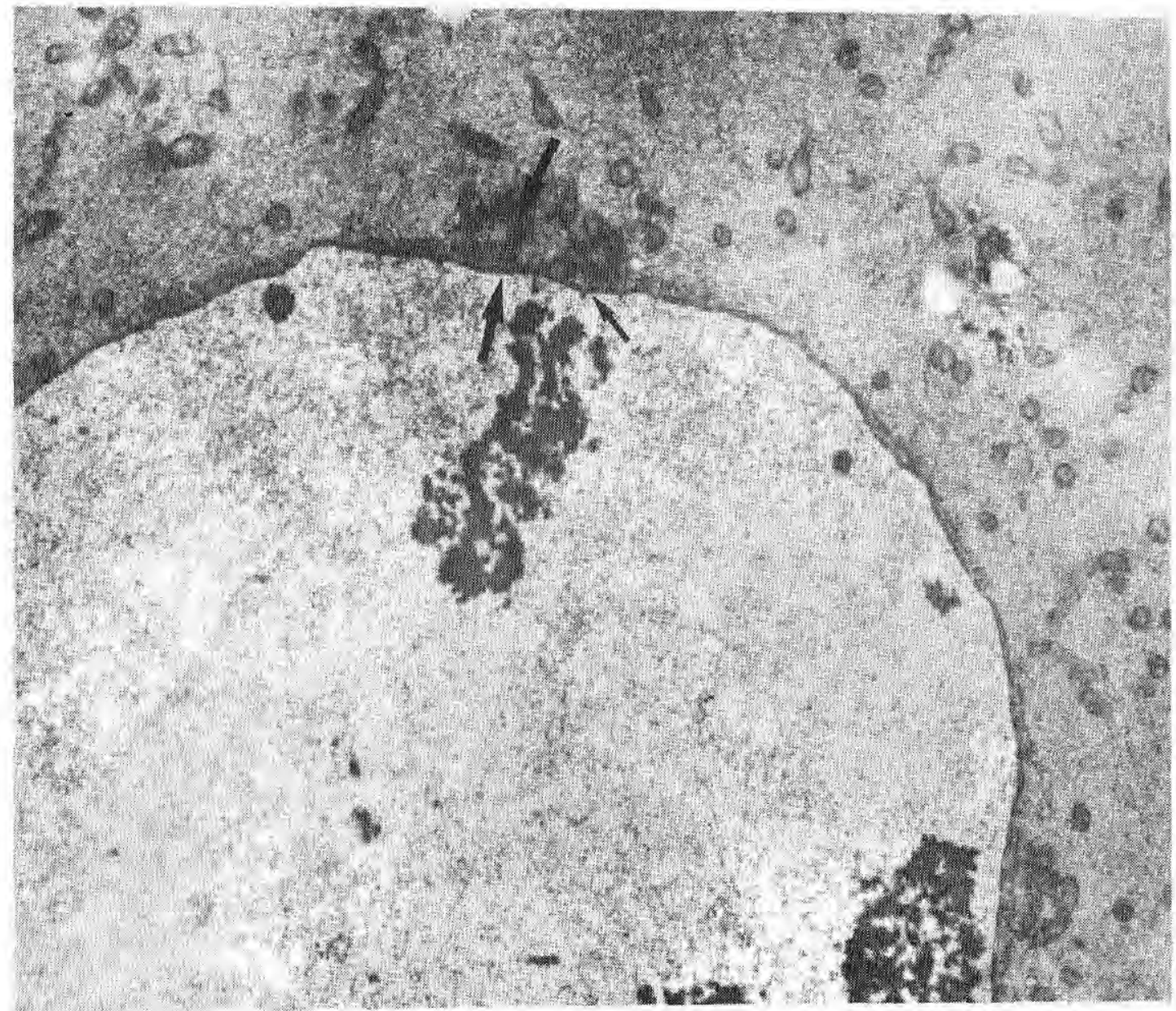

Fig. 3. Fotomicrografia com aumento maior de uma célula nutridora mostrando a passagem do material produzido no nücleo para o citoplasma. $14.100 \mathrm{X}$.

\section{DISCUSSÃO E CONCLUSÕES}

Nos insetos existem duas maneiras pelas quais as proteínas podem ser obtidas pelo ovócito. Na primeira, exögena, as proteínas são sintetizadas no corpo gorduroso e são transportadas pela hemolinfa até o ovócito, como demonstrado em värios insetos: Aedes (Roth \& Porter, 1964; Hagedorn et al., 1973), Periplaneta (Anderson, 1964), Panorpa(Bier \& Ramamurty, 1964), Platysamia cecropia (Telfer, 1954), Lygeus kalmi i (Kessel \& Beams, 1962), Hyalophora cecropia (Stay, 1965), Schistocerca (Hill, 1962), Lepismachilis (Bitsch, 1980). No segundo caso, o processo é endögeno e as proteínas são sintetizadas pelo pro prio citoplasma do ovócito como ficou evidenciado nos estudos de Cummings \& King (1970), em Drosophila, e em Hyalophora e Rhodnius por Telfer et al. (1982). Em Bombyx terrestris o processo é intraovariano, mas não endögeno (isto é no interior do ovócito), pois a forma ção das proteínas ocorre nas células foliculares (Hopkins \& King, 1966). Assim, combase 
nas evidências aqui apresentadas, em Anopheles a obtenção das proteínas provavelmente ocorre por um processo exógeno, conforme as indicações morfolögicas obtidas. Consideran do essas evidências, a formação dos grânulos de proteínas no citoplasma do ovócito ocorre por pinocitose de substâncias presentes na hemolinfa e carreadas através dos espaços in tercelulares das células, foliculares, como na maioria dos insetos. Não está descartada a possibilidade das cêlulas foliculares terem algum papel na vitelogênese, visto o aspec to de seus núcleos e nucléolos e as interrelações com os ovöcitos. Em uma primeira fase de formação das vesículas, o material eletrodenso exógeno se acumula no lado externo dc ovöcito e,posteriormente, avança por invaginações para o interior do mésmo. 0 estrangu lamento dessas projeções dá origem às vesículas revestidas, possivelmente, em ummecanis mo semelhante ao verificado por Ma \& Ramaswamy (1987) em Lygus lineolaris. 0 material eletrodenso é incorporado em vesículas maiores até originar os grânulos proteícos.

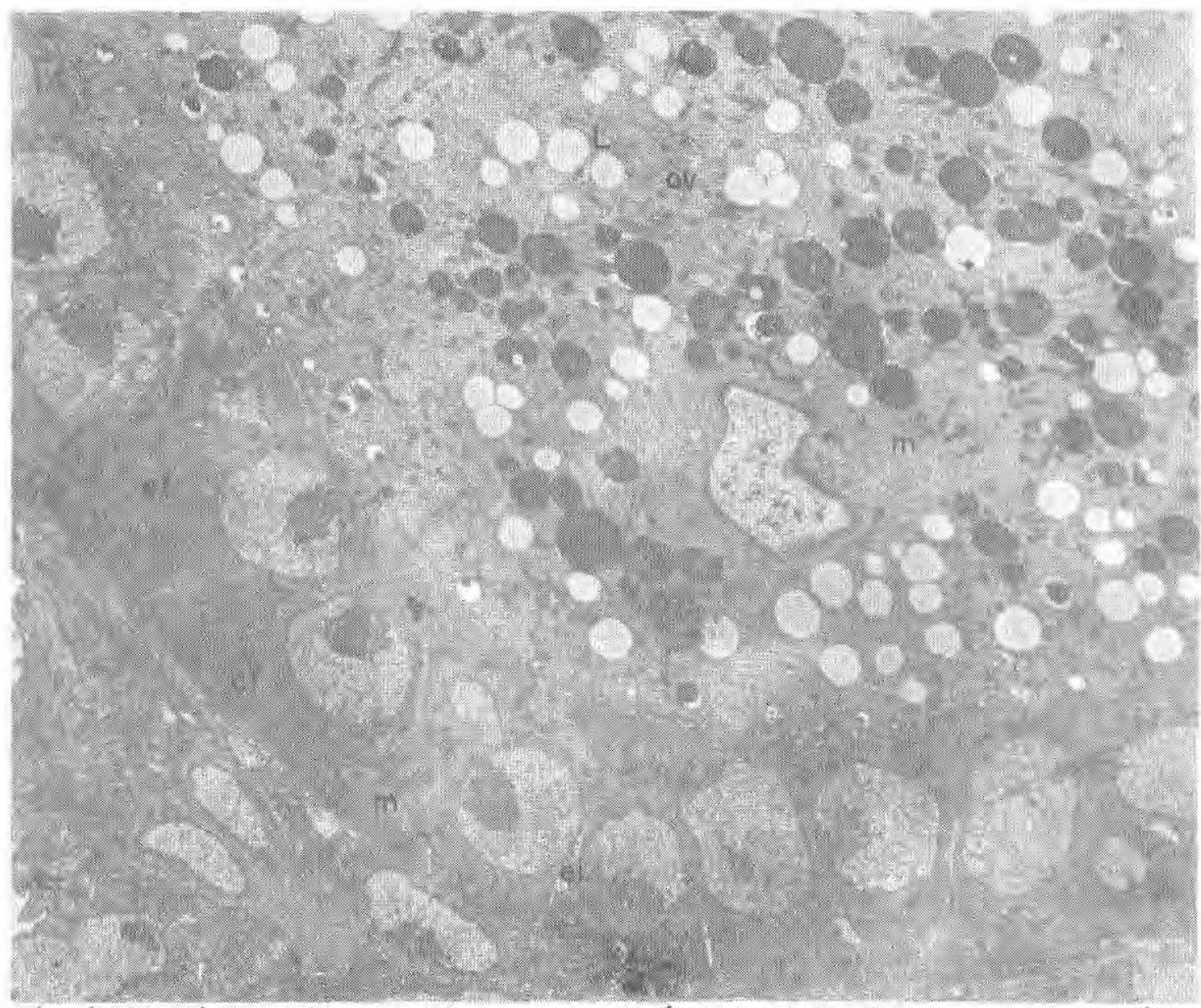

Fig. 4. Fotomicrografia mostrando parte do epitélio folicular (ef) associada ao ovócito (ov. As células foliculares (cf) são separadas pelo espaço intercelular (ei). O ovócito apresenta grânulos de lipídeos (L) emitocôndrías (m) $5.400 \mathrm{X}$. 
Segundo a literatura, canais extracelulares entre as células foliculares podemoca sionar um fácil acesso de todo material externo da hemolinfa, que atravessa a membrane basal (lâmina própria do ovário), uma vez que já foi demonstrada a existência de precur sores do vitelo fora do ovócito (Engels, 1974; Simões, 1980). Em Anopheles não foram ob servados espaços tão proeminentes como em Aedes aegypti (Roth \& Porter, 1964) e Hyalopho ra cecropia (Stay, 1965), mas isso não significa a falta de acesso davitelogenina da he molinfa. Um fato que também corrobora a hipótese da passagem de material externo para - ovócito é que esses espaços não foram encontrados entre as células foliculares em con tato com as células nutridoras (Figura 1). Em Aedes, esses espaços iniciam-se 7 horas apös a alimentação sanguínea (Roth \& Porter, 1964).

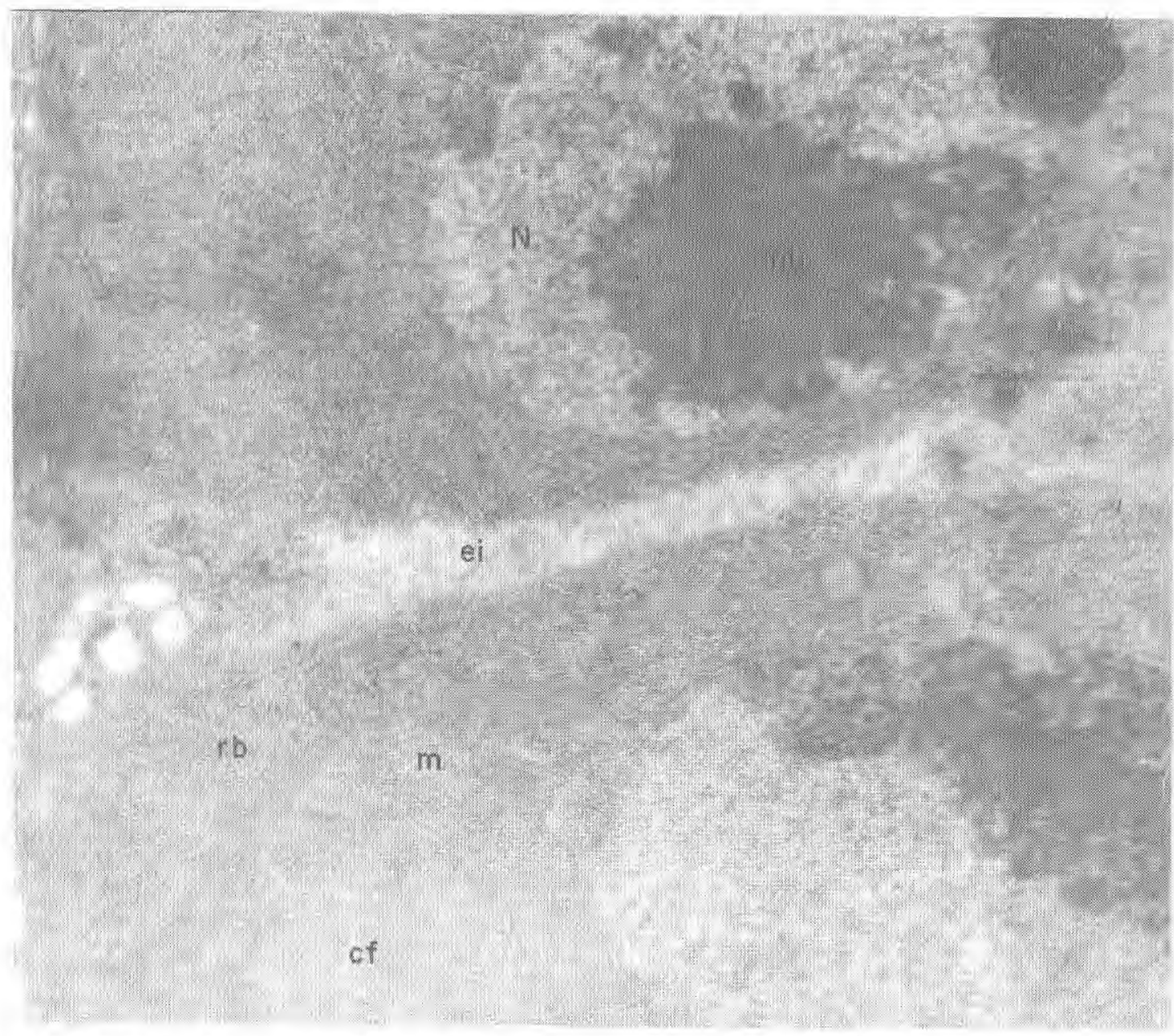

Fig. 5, Fotomicrografia detalhada da passagem do material floculento para o ovócito pe lo espaco intercelular (ei), entre as células foliculares (cf). Nücleo (N); nucléolo (nu); ribossomos (rb); mitocondrias (m); $37.800 \mathrm{X}$. 
Após o repasto sanguíneo, conforme assinalam Hagedorn et al. (1973), o desenvolvi mento do ovo pode ser regulado ao nivel do corpo gorduroso, quando da síntese das vitelogeninas; e ao nível da incorporação das proteínas, pelo ovócito. Nesta óptica, a aná lise dos diferentes niveis de desenvolvimento do ovo torna-se relevante, pois proporcio na dados sobre a evolução da reprodução do inseto, principal faceta interrelacionadacom a transmissão da malâria.

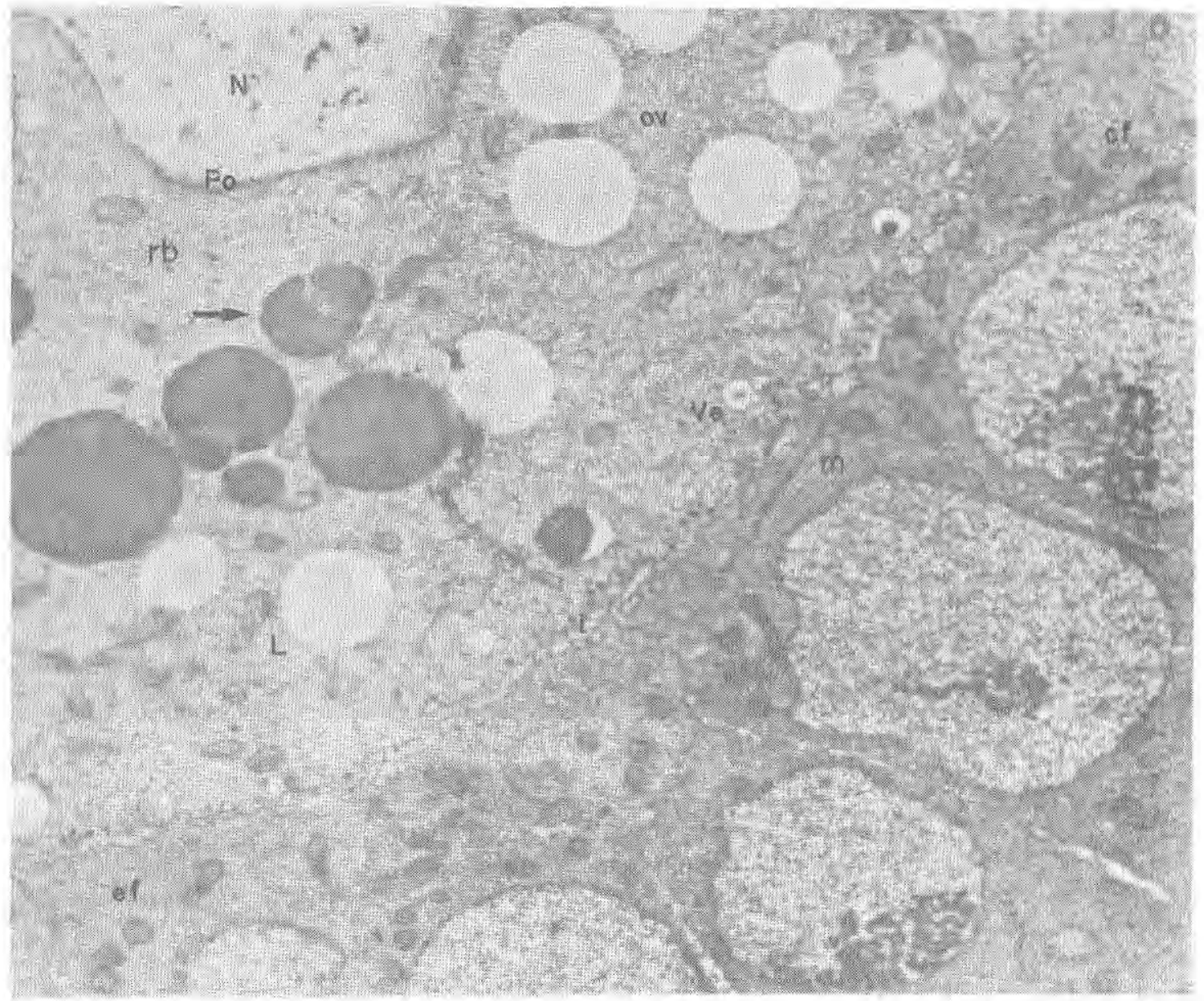

Fig. 6. Fotomicrografia da interface entre ovócito (ov) e epitélio folicular (ef). As células foliculares (cf) apresentam grande nümero de mitocôndrias (m) em seu ci toplasma. O núcleo (N) do ovócito mostra o envelope nuclear com poros ( $\mathrm{Po}$ ). No contato entre células foliculares e ovöcito são freqüentes invaginaçães ( $(\dot{)})$ com conteúdo denso. Vesículas (ve) derivadas dessas invaginaçōes coroam o cór tex do ovócito (ov) e originam os grânulos protéicos através da fusão entre elas (seta). Lipídeos (L), mitacondrias (m) e ribossomos (rb) também são encontrados no citoplasma do ovócito. $14.100 \mathrm{x}$. 


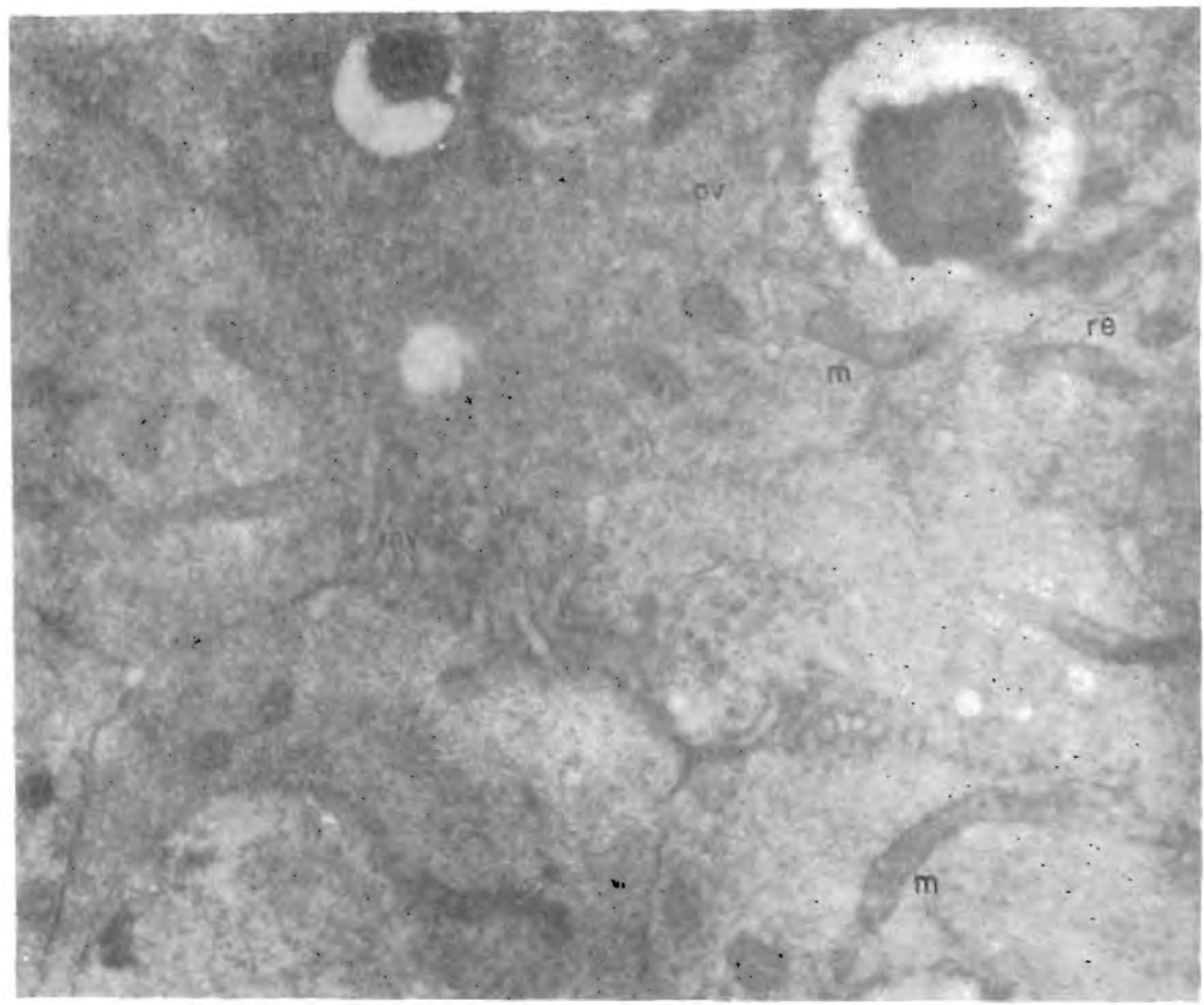

Fig. 7. Neste corte observantse as microvilosidades que se estendem da superfície do ovócito. Intre as microvilosidades (mv) existem värios pequenos grânulos que originam vesículas (ve) que se funder para format grānulos protéicos (P). Noci toplasma do ovócito (ov) observa-se o retículo endoplasmático (re) e mitocondrias $(\mathrm{m}) .24 .000 \mathrm{x}$. 


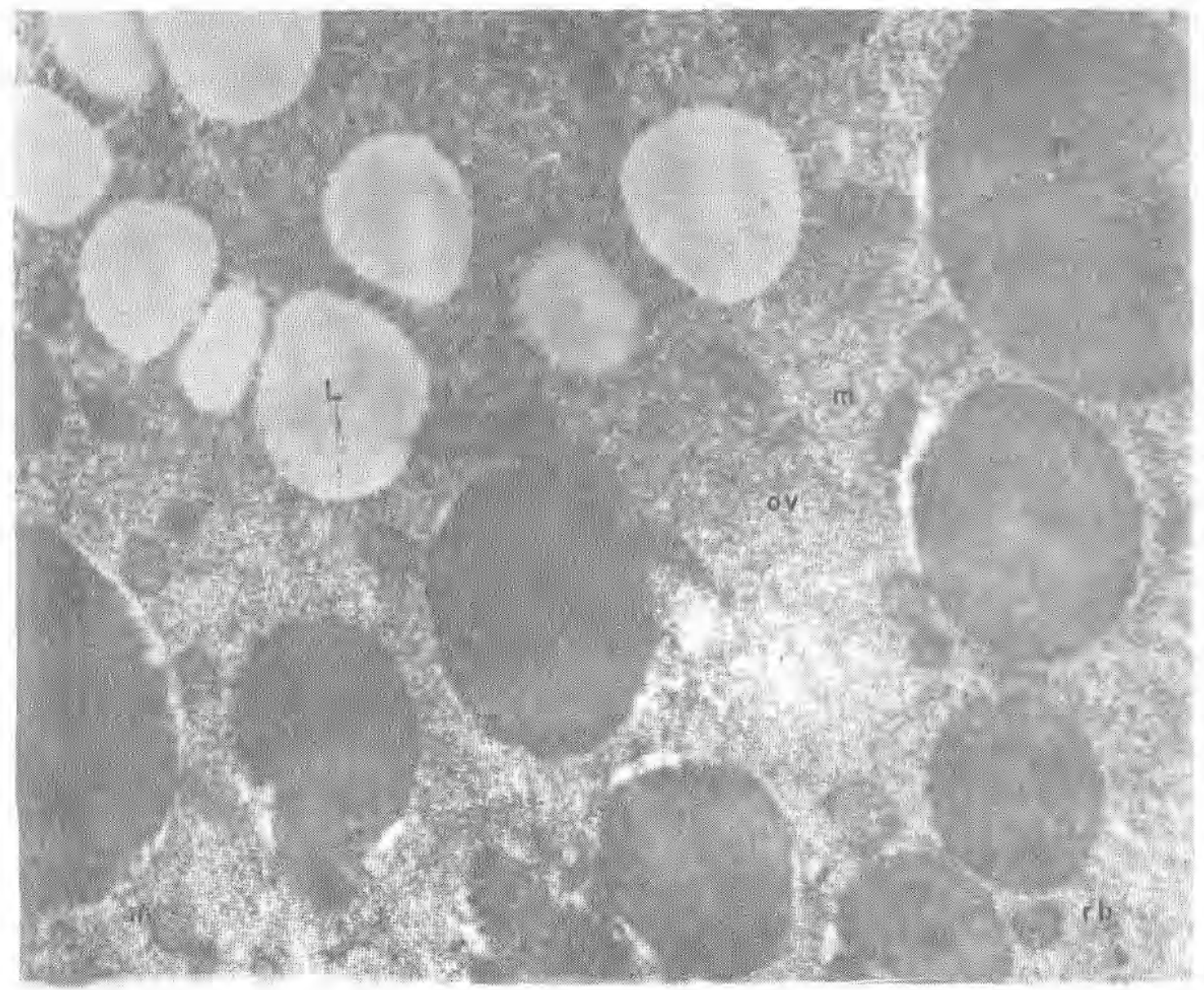

\#íg. 8. Fotomicrografia mostrando a fusão dos grăos de proteína (P) no citoplasma do ovócito (oy), junto ao grãos de lipídeos (L). Maturação de 48 horas. Mitocôndrias (mi) e Ribossomos (rb) . 27,000 X. 


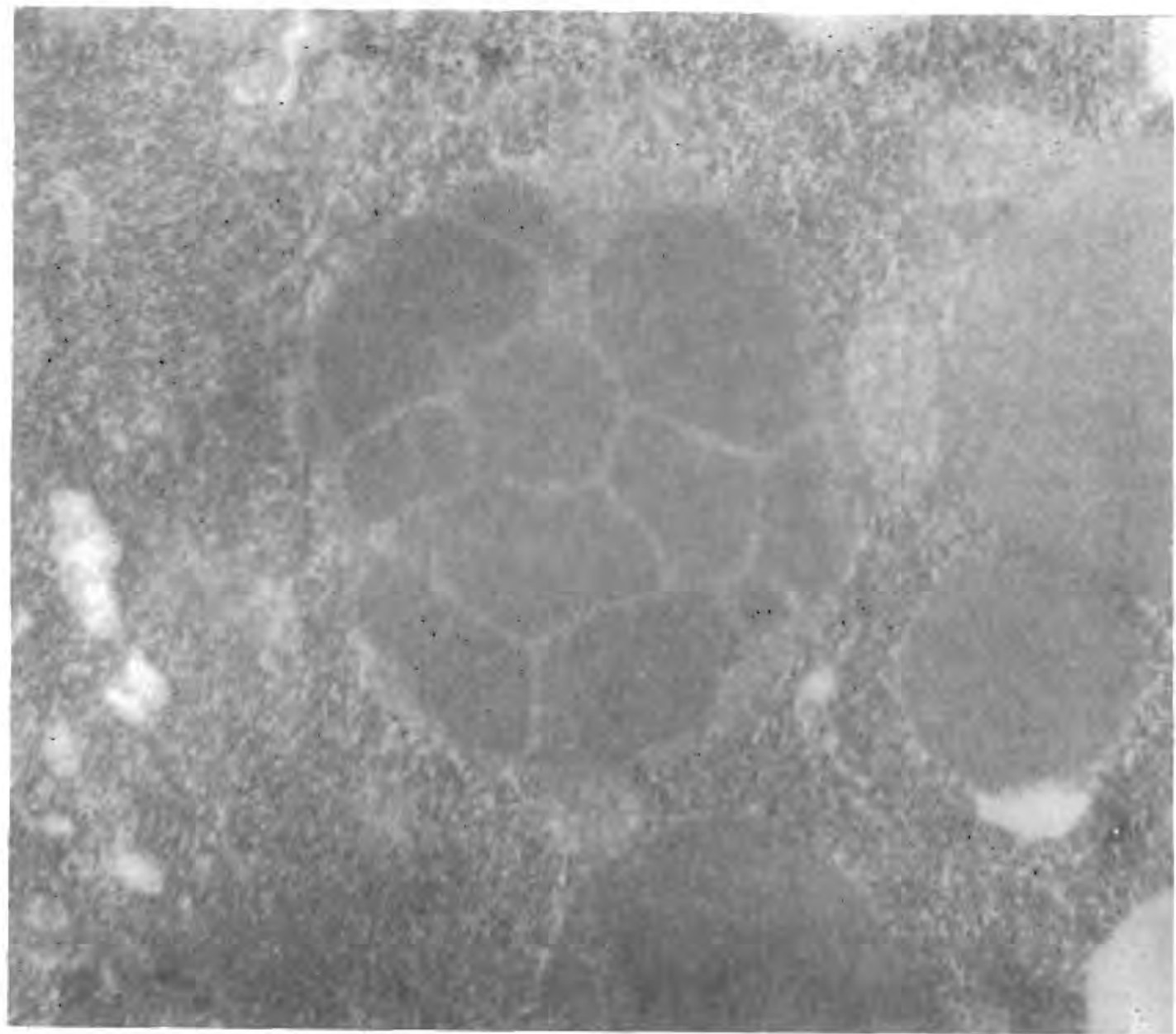

Fig. 9. Fotomicrografia mostrando en detalhe a configuração cristalina que o grânu! protéico assume, quando maduro. (maturação de 48 horas). $60.900 \mathrm{X}$.

\section{SUMMARY}

Ovaries of Anopheles triannulatus were dissected 24 h and $48 \mathrm{~h}$ afier a bioodmeat in order to study its effect on oogenesis. Histological sections were analized by electron wicrosecpy and the norphological changes ocurring at the oocyte - follicular epithelium and follicukar cell interface were observed. Structural aspects support the hypothesis that yolk proteins are produced outside the ovary. Prorein granuies arise mainly bu fusion of pit-vesicies formed at the oocyte surface. 


\section{Referências bibliográficas}

Anderson, E. - 1964. Oocyte differentiation and vitellogenesis in the roach Periplaneta americana. J. Ce11. Biol., 20:131.

Anderson, L. M. \& Telfer, W. H. - 1969. A follicule cell contribution to the spheres of moth oocytes. Tissue and Ce11, 1:633-644.

Bier, K. \& Ramanurty, P. S. - 1964. Elektronoptische untersuchungeni zur Finlagerung der notterprotein in die Docyte. Naturwissenschaften, 51:223.

Bitsch, J. - 1980. Ultraestructure des ovocytes et vitellogenese chez Lepimachilis tar gionii (Grassi) (Thysanura: Machilidae). Inst. J. Insect Morpho1 \& Embryol., 9:297313.

Brooks, V. J. - 1969. The induction of yolk synthesis in fat body of an insect, teuco phaea maderae, by a analog of the juvenile hormone. Develop. Biol., 20:459-471.

- 1976. Protein synthesis in fat body of Leucophaea maderae during vitellogenesis. J. Insect. Physiol, 22:1649-1657.

Christophers, S. R. - 1911. The development of the egg follucle in anophelines, Paludism, $2: 73-89$.

Cummings, M. R. \& King, R. C. - 1970. The citology of the vitellogenic stages of oogene sis in Drosophila melanogaster. II. U1trastrutural investigations on the origin of the protein yolk spheres. J. Morphol, 130:467-477.

Engelmann, F, - 1969. Female specific protein biosynthesis controlled by corpus allatum in Leucophaea maderae. Science, 105:407-409.

-.. 1971. Juvenile hormone - controlled synthesis by female specific protein in the cockroach Leucophaea maderae. Arch. Biochem. Biophys, 145:439-447.

Enge1s, W. - 1974. Occurrence and significance of vitellogenin in female castes of social Hymenoptera. Amer. Zool., 14:1229-1237.

Guelin, M. \& Durand, M. - 1980. Evolution des cellules nourricières au coure de l'ovo genèse chez Ephestia kukniella Z. (Insecte, Lépitoptère). Ann. Scien.Nat.,Zoologie, Paris, 13(2):167-207.

Hagedorn, H. H.; Falton, A. M.; Laufor, H. - 1973. Vitellogenin synthesis by the fat body of the mosquito Aedes aegypti; evidence for transcriptional control. Develop. Bio1, 31:285-294.

Hagedorn, H, H. \& Judson, C. L. - 1972. Purification and site of synthesis of Aedes aegypti yolk protein. J. Exp. Zool., 182:367-378.

Hi11, L. - 1962. Neurosecretory control of hemolymph protein concentration during ovari an development in the desert locust. J. Insect Physiol., 8:609-621.

Hopkins, C. R. \& King, P. E. - 1966. An electron microscopical and histochemical study of the aocyte perifery in Bombyx terrestris during vitellogenesis. J. Ce11. Sci., 1: 201-216.

Kessel, R. G. \& Beams, H. W. - 1962. Micropinocytosis and yolk formation in oocytes of the small milkweed bug. Exp. Ce11. Research., 30:440.

Ma, W. K. \& Ramaswamy, B. - 1987. Histological changes during ovarian maturation in the tarnished plant bug, Lygus lincolaris (Palisot de Beauvois) (Hemiptera: Miridae). J. of Insect Morphology \& Embriology, 16(5/6):309 322 . 
Mer, G. G. - 1936. Experimental study on the development of the ovary in A. elutus Edw. (Dip. Culic.). Bul1. Entom. Res., 27:351-356.

Reynolds, E. F. - 1963. The use of lead citrate at high pH as an electron opaque staim in electron microscopy. J. Ce11. Biol., 17:208-212.

Roth, T. F. \& Porter, K. R. - 1964. Yolk protein uptake in the oocyte of the mosquito Aedes aegypti (L.). J. Cel1 Biol., 20(2):313-332.

Shigematsu, H. - 1958. Synthesis of blood protein by the fat body in silkworm, Bombyx mori L. Nature, 182:880-882.

- - 1960. Protein metabolism in the fat body of the silkworm Bombyx mori L. Bu11. Sericult, Expt, Sta. Japan, 16:141-170,

Simões, Z. L. P. - 1980. Estudo de vitelogenina e da vitelina em Apis mel1ifera L. (Hy menoptera: Apoidea). Tese de doutoramento apresentada à Fac. Med. (USP) Ribeirão Pré to. SP. $108 \mathrm{p}$.

Stay, B. - 1965. Protein uptake in the oocyte of the cecropia moth, J. Cell Biol., 26 (1) $: 49-62$.

Telfer, W. H.; Huebner, E.; Smith, D. S. - 1982. The cell biology of vitellogenic folli cles in Hyalophora and Rhodnius. In: Insect ultrastructure. King, R. C. \& Akai, H. (eds, ). Plonum Press. New-York. 1:118-149.

Telfer, W. H. - 1954. Inmmological studies of insect metamorphosis. II. The role of a sex-limited female protein in egg formation by the cecropiasilkworm. J. Gen.Physiol., $37: 539-558$.

- 1960. The selective accumulation of blood proteins by the oocytes of saturniid moth. Bio1. Bu11., 118:338-351.

-... 1965. The mechanism and control of yolk formation. Ann. Rev. Entomo1,, 10:161184 .

Wigglesworth, V. B. - 1943. The fate of hemoglobin in Rhodnius prolixus and other blood - sucking arthropods. Proc. R. Soc. (London), Ser. B, 131:313-339. 